\title{
Migrant workers falling through cracks in health care coverage
}

\author{
n Cite as: CMAJ 2020 July 13;192:E819-20. doi: 10.1503/cmaj.1095882
}

Posted on cmajnews.com on June 26, 2020.

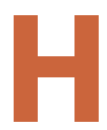

ealth workers and human rights advocates are urging the federal and provincial governments to extend public health insurance to all people living in Canada, regardless of immigration status, as outbreaks of COVID19 among migrant workers escalate.

In one recent open letter, more than 200 organizations, including the Canadian Medical Association, College of Family Physicians of Canada and the Canadian Paediatric Society, warned that "we place our entire society at risk by failing to guarantee health care to all people."

More than 600 migrant farmworkers in Southwestern Ontario have tested positive for COVID-19, and three have died in recent weeks. Migrant rights groups say overcrowded accommodations, a lack of protective gear, and pressure from employers to work while sick have contributed to the spread of the virus. Some farmers have also resisted efforts to increase testing for COVID-19 among migrant workers, out of concern that those who test positive will be unable to work.

Many migrant workers have precarious access to health care and coverage that is dependent on a specific employer. Those laid off for any reason, including due to illness or injury, may lose health coverage or avoid seeking care for fear of being deported.

"It's not just an individual issue, it's a public health issue," says Bukola Salami, an associate professor of nursing and expert in health and migration policies at the University of Alberta. It's difficult to trace and isolate migrant workers with COVID-19 if they're unable to access care.

The problem extends to thousands of people living in Canada with precarious

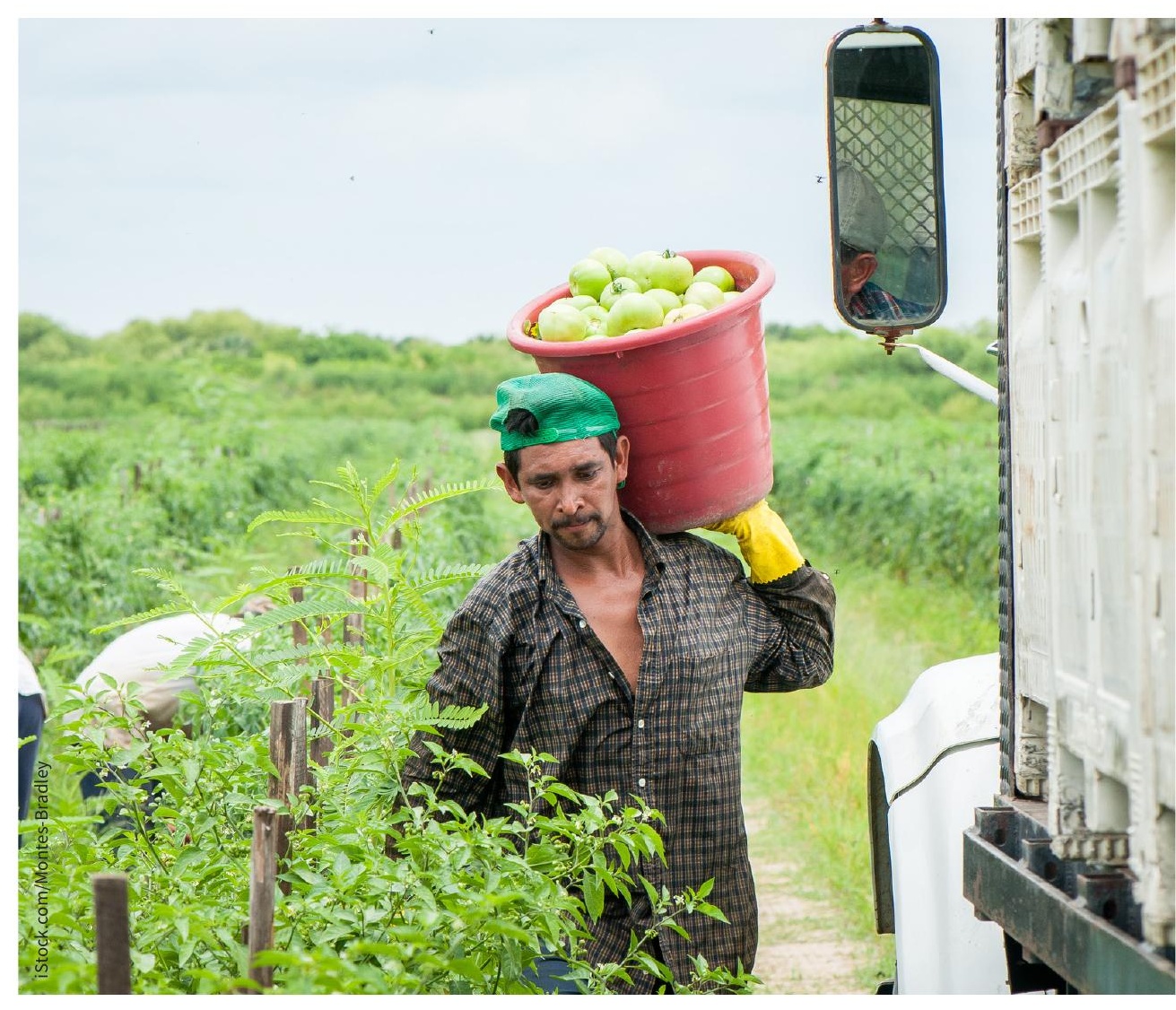

Precarious health coverage and immigration status have made migrant workers especially vulnerable to COVID-19.

immigration status, including international students, rejected refugee claimants and people without documentation.

Marjorie Carmona Newman, an immigration consultant based in Edmonton, says the mental health of many of her clients has suffered during the pandemic. With families to support in other countries, most are desperate to keep their jobs, making them vulnerable to exploitation and unsafe working conditions.

Take, for example, the situation at meat processing plants in Alberta, which employ many temporary foreign workers.
Despite the adoption of some infection prevention guidelines, one plant in High River had people working "elbow to elbow." The ensuing outbreak of COVID-19 was one of the largest in Canada tied to a single site.

Some provinces, including Ontario, British Columbia and Quebec, have expanded public health insurance to uninsured people during the pandemic. However, advocates say these measures are temporary and, in some cases, only cover services related to COVID-19. And implementation has been patchy. 
According to Dr. Arnav Agarwal, a resident physician in Toronto and advocate with OHIP for All, a lack of communication about expanded public coverage during the pandemic has meant some hospitals and clinics are still billing patients directly.

"We know through extended networks that there are patients in Ontario who have been turned away from accessing care without insurance or been asked to pay," Agarwal says. Other provinces, such as Alberta and Nova
Scotia, haven't yet addressed gaps in coverage for people with precarious immigration status.

Along with the other signatories of the recent open letter, Agarwal is calling for permanent and truly universal coverage for all medically necessary services regardless of immigration status, and a public information campaign to inform uninsured people that care is available at no charge. More than 7500 people have signed a petition urging similar action.
Migrante Alberta director Marco Luciano says that because people with precarious immigration status are fearful of being deported, public messaging must be exceptionally clear that anyone can seek help without penalty or barriers, such as needing to provide identification.

"Basic health care should be accessible to all," he says. But for now, "it's still a privilege, and there are still big gaps and holes that people keep falling into."

Sabrina Doyle, Hinton, Alta. 